\title{
Validation of Sequential Problem Test (SPT) for Identification of the Children with Specific Learning Difficulties
}

\author{
Tariq Mahmood Khan ${ }^{1}$, Ahmed Sher Awan ${ }^{1} \&$ Muhammad Naeem Mohsin ${ }^{3}$ \\ ${ }^{1}$ Department of Secondary Education, Institute of Education and Research, University of the Punjab Lahore, \\ Pakistan \\ ${ }^{3}$ Department of Educational Sciences Islamic Religious Pedagogy, University of Vienna, Austria \\ Correspondence: Tariq Mahmood Khan, Department of Secondary Education, Institute of Education and \\ Research, University of the Punjab Lahore, Pakistan. Tel: 92-321-943-4380. E-mail: drtariq@dr.com
}

Received: August 14, $2011 \quad$ Accepted: October 24, $2011 \quad$ Online Published: January 18, 2013

doi:10.5539/jedp.v3n1p64 URL: http://dx.doi.org/10.5539/jedp.v3n1p64

\begin{abstract}
This paper will develop an insight into the role of a teacher to identify the children with Specific Learning Difficulties (SLD) among the students in mainstream classrooms. It will enhance the quality of teacher education of the teachers working in the regular classrooms without knowing the specific learning difficulties of the students through the valid instruments and procedures. The presentation will discuss the report on the Validation of Sequential Problem Test (SPT) for identification of children with Specific Learning Difficulties from regular school classroom with purposive sampling techniques. The test was validated by the advance statistical measures. IQ and classroom achievements in Urdu were adopted to determine criterion \& discriminant validities as procedures. For stability reliability, test retest reliability was used. Internal consistency was determined through Scale of Reliability Cronbach's alpha coefficient. Item Characteristics Curve (ICC) by score for each item of the tests with zero and one response was drawn for item fitness.
\end{abstract}

Keywords: specific learning difficulties, validation, sequential problem test, IQ, classroom achievements, criterion validity, discriminant validity, retest reliability, item characteristics curve, Cronbach's alpha coefficient

\section{Introduction}

Schoolchildren with deficiencies in different academic achievements in reading, writing and spelling usually perform their daily life activities better than to their academic achievements. They commit some common mistakes in reading words; omit some letters during reading activity or writing after copying it from any source. Such types of problems of the children affect them of academic achievements in subjects in which such basics of reading and writing are involved. If there is no problem of vision and auditory abilities with these children, then they are declared SLD in one or more specific areas of learning.

It is one of the major problems of the exceptional children especially with learning disabilities in Pakistan that they are not properly diagnosed and treated according to their specific difficulties in specific areas. Children with SLD cannot perform well in verbal tasks and they are not fairly good at non-verbal ability performance tasks. Especially their performance in academic assignments is not good. The teacher often does not know the nature of their problems, which are causing trouble in doing assignments of different nature. Children with difficulties face problem in interpretation of the words after seeing them from the board, notebook or from any other source and are unable to reproduce the same word or respond to as properly as required. Such types of problems of the children are becoming hindrances in their classroom performance. Teachers are assessing performance of their students without knowing their real deficiencies in verbal and non-verbal areas of achievement. They treat and even punish them harshly considering that students are lazy and dull without knowing the factual cause of their deviant performance. Many of the children cannot cope with circumstances developed by the teacher as a result of incompetency in assessing students. Consequently students quit their further education. Actually most of these students are at risk of Specific Learning Difficulties. Lerner (2000) reported that the percentage of SLD among all disabilities is 51.10.this rate was noted in the US Department of Education Annual Report, 1998 that was presented to Congress on the implementation of the Individuals with Disabilities Education Act. This is the highest percentage as compared to all other categories of disability. In Pakistan, the literacy rate at primary level is not encouraging. No exact statistics for the prevalence of SLD are available. However, literacy rate in Pakistan, 
according to the Literacy Commission of Pakistan, Ministry of Education Govt. of Pakistan (2000) is only $47.2 \%$. On the other hand, the dropout rate in primary education in Pakistan is high. It was reported in the daily Dawn (2002) that $50 \%$ children enrolled in primary schools dropped out before completing grade five. This is one of the major reasons for failures in upgrading the standards of education in Pakistan. Lack of identification of the children with SLD might be another of the causes. In Pakistan, the teachers adopt no remedial measures to cater the problems of these children because identification tools are not available.

\section{Literature Review}

There are many areas in which the dyslexics have difficulties. These difficulties vary in severity and intellectual ability of the child. According to Pollock \& Waller (1995) frequency of sequencing and spatial relationship difficulties in the dyslexic is high. Sequencing is doing things or putting things in their correct order and following directions. It is observed that children with SLD frequently show that they are not having the idea about order of months. Doyle (2002) described that in the survey, 55 percent of the total could not recite the month of the year in correct order. As far as identification of right and left is concerned, the dyslexic showed not only higher rate of confusion with right and left but also about their body parts, i.e., right leg, left ear, right eye, etc. On the other hand they have problem with the sequence of months of the year, days of the week, and words and digits.

Sequencing in ordering and orientation is related to spatial relationship that is another weak area of children with SLD. Pollock and Waller (1995) described that there were problems in relating the position of one object to another object in dyslexics. So they showed the problem in knowing from where to begin to read, and write, as well as difficulty with order of the letters or syllables in a word. It shows that the child's comprehension is also affected.

Assessment of children with SLD is not so simple. Their problems in reading and writing are multi facet. They have different backgrounds for these problems. There should be equal opportunities of education for these children without economic problems. That hinders their acquisition of reading writing ability. Spafford \& Grosser (1996) suggested that for screening "culture-free test" is not recommended. For the diagnostic tests of SLD, equal opportunities of education and uniformity in economic resources are necessary.

The assessment of children with SLD can be ensured by comparing IQ test scores with the school achievements. Washington (1994) indicated that learning disorder is diagnosed when the individual's achievement on individually administered that of standardized tests in reading, mathematics, or written expression is substantially below than expected for age, schooling, and level of intelligence. The learning problems significantly interfere with academic achievement or activities of daily living that require reading, mathematical, or writing skills.

Discrepancy between the different tasks in reading, writing and school achievements leads us to the diagnosis of these children. According to the web team (2003) Department of Psychology, University of Kentucky, UK, the common features of the dyslexia are: the significant discrepancy between verbal and written performance; misreading when copying or taking notes; trouble in following a sequence or keeping pace when reading; problems in ordering things sequentially and persistent or severe problems with spelling. Mann and Suiter (as cited in Alper, Ryndak \& Schloss, 2001) developed Handbook in Diagnostic Teaching, which is seemed to be a good source of the idea about informal spelling and reading assessment. Smith's (as cited in Alper, Ryndak \& Schloss, 2001) Teacher Diagnosis of Educational Difficulties was also a source, which included the areas of spelling, reading, written expression, speech and language, arithmetic and personal emotional-social skills. Dyslexia Association of Ireland (2003) has given the following criteria for the psycho- educational assessment of the dyslexia: 1-Contact the child's school, which may agree that a problem exists. 2-Have the child's hearing and sight tested to ensure that there are no acuity problems. 3-Arrange for a psycho-educational assessment with a qualified psychologist.

This should describe the nature and extent of the problem and offer specific advice on remediation. Before attending assessment meetings make a list of the child's earlier and current problems and take it along. A teacher's report is always very helpful in this process.

Blamires (2003) has recommended the diagnosis of Specific Learning Difficulties to see the extreme discrepancy between the attainment in different core subjects of the national curriculum or within one subject, particularly, language reading or spelling and standardized tests of cognitive ability and oral comprehension.

In the light of above discussion, Specific Learning Difficulties can be defined children having average I.Q, the significant discrepancy between general ability and achievements in one or more school subjects like spelling, 
reading and writing in Urdu language. There are no other disabilities and cultural disadvantages in these children.

\section{Purpose of the Study}

The objective of the study is to identify the sequential problem as associated feature of the students with Specific Learning Difficulties and develop a test to identify the sequential problem of the students. It would be a helpful tool in the assessment and diagnosis of students with SLD in the classroom.

\section{Methodology}

SPT Test of SLDS' was given to 169 students in which there were 50 boys and 119 girls, 91 from $6^{\text {th }}$ class and $7^{\text {th }}$ class with high scores on SLD Screening Checklist for Teachers (Mahmood, 2010), with I.Q. score between 90 and 110 and below 50\% classroom achievement in Urdu that is in the form of school grades in Urdu .Distribution of boys, girls and $6^{\text {th }}$ and $7^{\text {th }}$ grade students in the pilot study is given in table 1 of the cross tabulation count.

Table 1. Gender and class cross-tabulation count for pilot study

\begin{tabular}{lllll}
\hline & & $\begin{array}{l}\text { Class } \\
6^{\mathrm{TH}}\end{array}$ & $\begin{array}{l}\text { Class } \\
7^{\mathrm{TH}}\end{array}$ & Total \\
\hline Gender & Boys & 30 & 20 & 50 \\
& Girls & 61 & 58 & 119 \\
Total & & 91 & 78 & 169 \\
\hline
\end{tabular}

SPT Test of SLD was administered to students according to directions for each test. Directions were further made comprehensive, in the light of pilot study. The data collected from SPT Test of SLDS' was analyzed. Criterion validity was determined with the outside criterion while selecting school grades and ability IQ tests. Factor analysis was run to determine construct validity of SPT Test of SLD and validity was determined in the form of factorial validity. Item in each test were selected on the basis of factor loading ranging from .39 to .81 and their respective good reliability coefficients were determined through the Cronbach Alpha above the 0.5 value. Items of the tests having low loading like 0.39 were included in the test as their respective reliability coefficient Cronbach Alpha was .65. The items affecting the loading of the factor in factor analysis or reliability coefficient were excluded from the tests. Ability I.Q. Test Raven Progressive Standard matrix was administered to students having high score on SLD Screening Checklist for Teachers (Mahmood, 2010). Their school achievements in Urdu were collected from school record. The just last test score in Urdu was taken for further analysis.

\subsection{Population and Sample}

Population of the study was sixth and seventh grade male and female students of government schools of Lahore city. Teachers who were to report about the prior observation of the students having problem in one or more learning areas had been teaching Urdu to sixth and seventh grade students. The sample of the study was selected from the population while considering each school as cluster. These clusters were randomly selected, and 40 male and female government schools were selected for the study. In each school, teachers were consulted and purposive sample from the students was selected for the study. Those students who had problem in one or more learning areas related with definitional perspectives of SLDs were selected for the study. More than 2100 students were selected for the study but only 1013 students were selected for the whole procedures of the identification of SLD. The teachers reported rest of the students but they were not meeting the criteria for the eligibility for the SPT Test of SLDS'.

Most of them were not meeting the criteria of achievements or I.Q. test scores. They had visual or eyesight problem, or their parents were very poor and they did not maintain their studies with proper continuation. Some of them had remained abroad in countries of different languages like English and Arabic. Distribution of boys and girls in $6^{\text {th }}$ and $7^{\text {th }}$ grade students in the sample is given in the table 2 of cross tabulation count. 
Table 2. Gender and class cross-tabulation count of students

\begin{tabular}{lllll}
\hline & & $\begin{array}{l}\text { Class } \\
6^{\text {TH }}\end{array}$ & $\begin{array}{l}\text { Class } \\
7^{\text {TH }}\end{array}$ & Total \\
\hline \multirow{2}{*}{ Gender } & Boys & 433 & 269 & 702 \\
& Girls & 150 & 161 & 311 \\
\multirow{2}{*}{ Total } & & 583 & 430 & 1013 \\
\hline
\end{tabular}

\subsection{Content Validity}

For the content validity analysis of the tests judgmental validity was determined with the assistance of panel of experts having experience in Urdu language teaching, educational and psychological test construction and teaching.

\subsection{Construct Validity}

Factor analysis was run for the exploratory and confirmatory factor loading to map out the most important variables for the SPT for the confirmation of sub-tests to confirm the variables in the test as were selected in the exploratory factor analysis in the pilot test.

Table 3. Rotated component matrix of the confirmatory factors analysis for the factors for the identification of the SPT

\begin{tabular}{lll}
\hline TEST & Item No & Factor Loading \\
\hline SPT & 3 & 0.80 \\
SPT & 2 & 0.65 \\
SPT & 4 & 0.58 \\
SPT & 1 & 0.50 \\
\hline
\end{tabular}

It is indicated in table 3 that SPT test factor had four items for factor loading in confirmatory factor analysis ranging from .502 to .80 .

\subsection{Discriminant Validity}

This validity was established with the mean scores of the test SPT Test of SLD'S and between low and high scores categories on SLD screening checklist for teachers of the students. T-test was applied and the results of t-test for the independent sample are presented in table 4.

Table 4. Independent Samples t-test for comparison of low $(\mathrm{n}=37)$ and high $(\mathrm{n}=976)$ scoring groups of SPT ( $\max$ score $=4$ ) with achievement scores in Urdu and IQ

\begin{tabular}{llllll}
\hline Variables & Low & \multicolumn{3}{c}{ High } & t \\
& M & SD & M & SD & \\
\hline Scores in Urdu & 43.00 & 4.35 & 45.17 & 5.42 & $2.40^{* *}$ \\
IQ & 88.29 & 10.82 & 100.38 & 15.96 & $6.53^{* *}$ \\
\hline
\end{tabular}

$* * \mathrm{p}<.01$ Level of significance

Independent Samples t-Test for Comparison of Low and High Scoring Groups of SPT with Urdu Test Scores and IQ had t-values 2.40, and 6.53 respectively which are indicated in Table 4 . The t-values were significant at $\alpha$ $=.01$. Following null hypotheses were rejected 1-There is no significant difference between the Urdu test mean scores of students of low scoring (0) Group 1 and high scoring (1 - 4) Group 2 of SPT. 2-There is no significant difference between the IQ test mean scores of students of low scoring (0) Group 1 and high scoring (1 - 4) Group 2 of SPT. 


\subsection{Reliability}

Reliability of the test was determined with internal consistency and stability. The stability of the test is determined with the test retest type of reliability analysis. Consistency reliability of the test was determined with Cronbach Alpha of the factors obtained from the explanatory factor analysis of SPT which are given in table 5.

Table 5. Correlation coefficient between the pre and post tests of $(n=44)$ of the SPT test

\begin{tabular}{lll}
\hline Test & sig & r post test \\
\hline SPT & .001 & $.49^{* *}$ \\
\hline
\end{tabular}

It is indicated in the table- 5 that the test scores of pre test and posttest of the SPT Test of SLD'S score was had significant value .001 which was significant at .01 level of significance with .486 correlation value. So the null hypothesis that there is no significant correlation between pre test and posttest scores of the SPT Test was rejected as given in table 6 .

Table 6. Scale of reliability Cronbach's alpha coefficient for the identification of reliability coefficient SPT test of SLD'S

\begin{tabular}{llll}
\hline TEST & Number of Items & $\mathrm{N}$ & Alpha Reliability \\
\hline SPT & 4 & 1013 & 0.51 \\
\hline
\end{tabular}

It is indicated in the table- 6 that the Cronbach Alpha reliability coefficient for the reliability coefficient of SPT Test of SLD'S was 0.51 .

Table 7. Item response modeling item analysis of the SPT with zero and one response items $(\mathrm{N}=1013)$

\begin{tabular}{lccc}
\hline Tests \& Items & Discrimination & Item Threshold & Weighted MNSQ \\
\hline SPT-1 & .59 & .46 & 1.05 \\
SPT-2 & .60 & -.50 & 1.02 \\
SPT-3 & .76 & .32 & .90 \\
SPT-4 & .59 & -.28 & 1.02 \\
\hline
\end{tabular}

\subsection{Item Analysis}

Table 7 indicates that the discrimination levels of all items of the test ranged from .90 to 1.05 , which is acceptable range. The item threshold of all the items ranged from .28 to .50 , also shows relatively low difficulty range. It showed that all items in the test had discrimination power within range. Moreover, all items in the test had adequate item threshold /item difficulty within range.

Item Characteristics Curve (ICC) by score for each item of the SPT test with zero and one response was drawn for item fitness. Combined items curves for SPT are presented in Figure 1-4: 


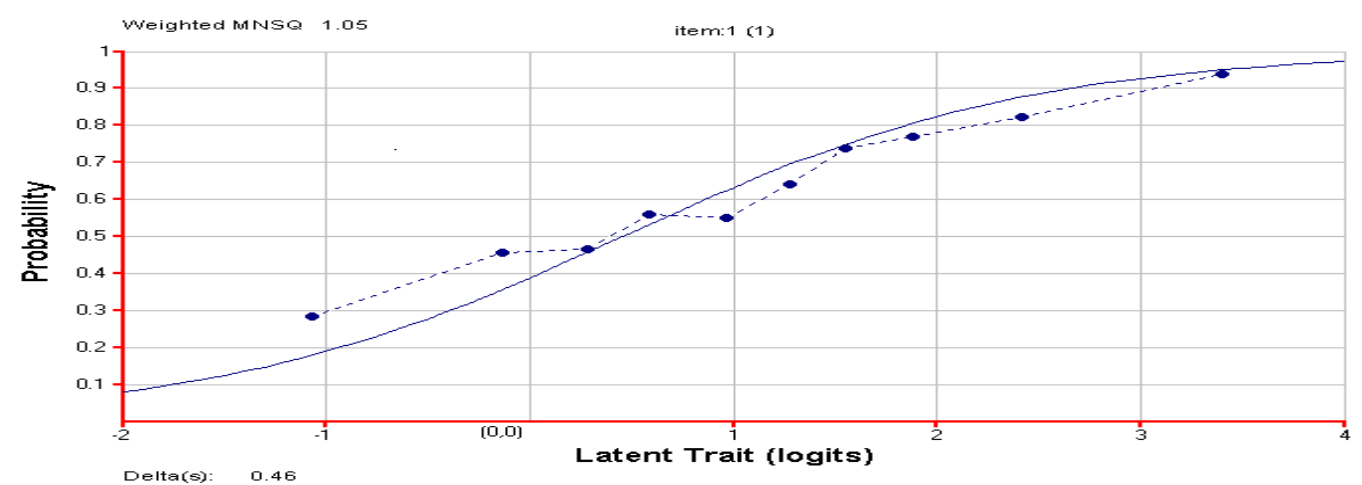

Figure 1. Item response modeling item characteristics curves by scores for SPT-1

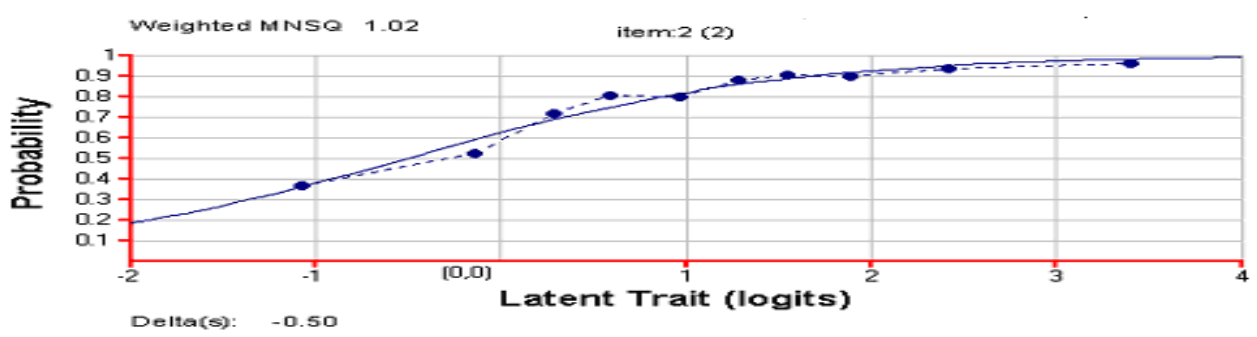

Figure 2. Item response modeling item characteristics curves by scores for SPT-2

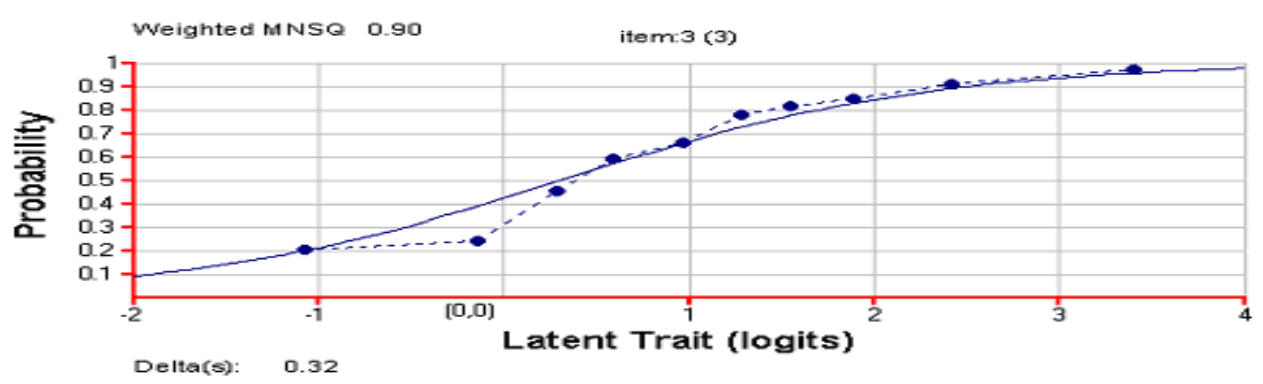

Figure 3. Item response modeling item characteristics curves by scores for SPT-3

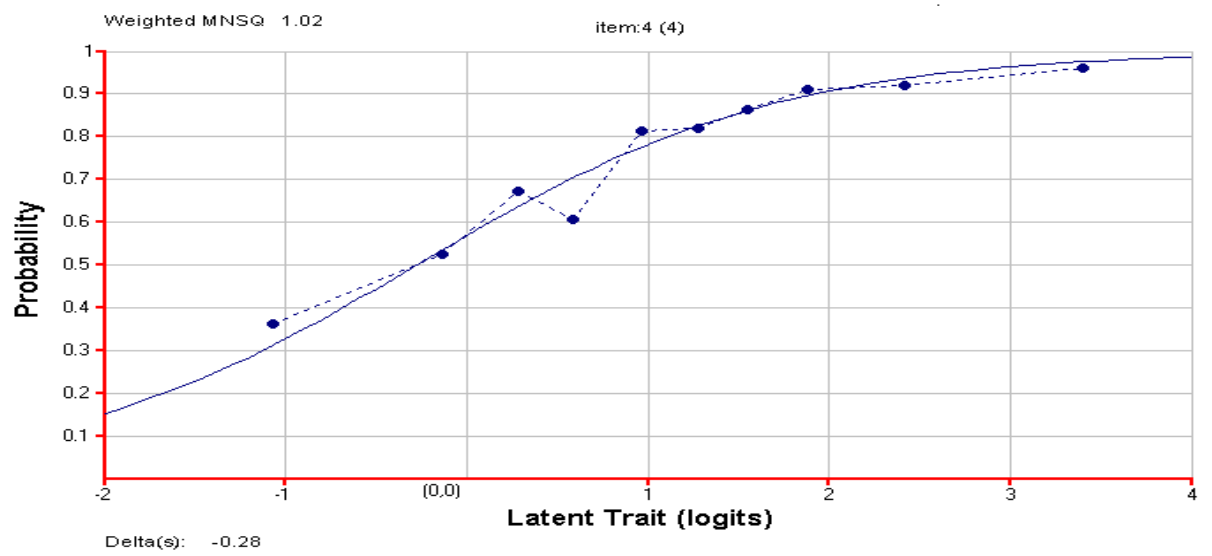

Figure 4. Item response modeling item characteristics curves by scores for SPT-4 
ICC of item SPT-1 was slightly flat with respect to the theoretical curve. This was acceptable range of difficulty. ICC of item SPT 2 was also slightly flat with respect to theoretical curve. This indicated low difficulty level. ICC of item SPT 3 was slightly flat with respect to theoretical curve. This indicated an acceptable difficulty level. ICC of item SPT 4 was slightly flat with respect to theoretical curve, which indicated low difficulty level of the item and it was an easy item.

\section{Discussion and Conclusions}

On the recommendations of the experts content and items of the test were finalized for further study and content validity was established. It was concluded that SPT test had sufficient factor loading for all items for factorial validity. It was further concluded that students of low scoring group and high scoring groups of the SPT were significantly discriminating in the mean scores of the scores in Urdu. So the discriminant validity of the SPT was established with the scores in Urdu. Students of low scoring group and high scoring groups SPT were significantly discriminating the mean scores of the IQ test. So the discriminant validity of the SPT was established with the IQ test. Test score of pre test and posttest of the SPT Test of SLD had significant correlation at .01 level of significance and stability reliability of the SPT Test of SLD'S was identified and SPT Test had sufficient reliability. Item Response Modeling Item Analysis of the SPT with Zero and One Response Items showed that all items in the test had discrimination power within range and all items in the test had adequate item threshold /item difficulty within range. Item Characteristics Curve (ICC) by score for each item of the tests with zero and one response was drawn for item fitness. ICC of items SPT-1 and SPT-3 was slightly flat that shows acceptable difficulty levels where that SPT-2 and SPT-4 was also flat but shows low difficulty level. Which indicated low difficulty level of the item and it was an easy item.

This discussion shows that this paper can contribute to the research for the identification of the Specific Learning Difficulties at the school level. School teachers can identify the students with specific learning difficulties and conduct more specific identification measures. Teachers can start intervention and investigate more sophisticated problems of the children having specific learning difficulties at the school level.

\section{References}

Alper, S. Ryndak, D., \& Schloss, C. N. (2001). Alternate Assessment of Students with Disabilities in Inclusive Settings. London: Allyn and Bacon.

Annastasi, A. (1997). Psychological Testing. New York: Macmillan Publishing Company.

Blamires, M. (2002). Specific Learning Difficulties. Retrieved from http://www.education resources.cant.ac.uk/xplanatory/approach/sldtcld.htm

British Dyslexia Association. (2002). Dyslexia. Retrieved from http://www.bda.dyslexia.org.uk/bogmaths/mol calc.htm/com

Cronbach, L. J., \& Meehl. P. E. (1955). Construct Validity in Psychological Tests. Psychological Bulletin, 52, 281-302.

Department of Psychology University of Kentucky Web Team. (2002). Retrieved from http://www.ukc.ac/psychology/tutoring/ dyslexia. htm

Doyle, J., \& Snowling, M. (2000). Dyslexia and Introductory Guide (2nd ed.). London: Whurr Publishers Ltd.

Dyslexia Association of Ireland. (2002). Dyslexia. Retrieved from http://www.dyslexia.ie/index.htm

Garson G. D. (2004). Factor Analysis in Stat: An online text book. Retrieved from http://www 2.class nesu.edu./garson/pa 765/stat note.htm

Gregory, R. J. (1996). Psychological Testing. USA: Allyn \& Bacon.

Grounlund, N. E., \& Linn, R. L. (1990). Measurement and Evaluation in Teaching. New York: Maxwell Macmillan Publishing Co.

Kline, P. (2000). Handbook of Psychological Testing (2nd ed.). London: Routledge.

Lerner J. (2000). Learning Disabilities (8th ed.). New York: Houghton Mifflin Co.

Mahmood, T. (2010). Validation of Procedures for Identification of the Children with Specific Learning Difficulties in Mainstream Classrooms. Bulletin of Education and Research, 32(2), 93-101.

Moddy. S. D. (2002). Dyslexia online journal-Dyslexia: A Psychotherapist grade. Retrieved from http://www.dyslexia.therapy.html

Murphy, K. R., \& Davidshofer, C. O. (1988). Psychological Testing. USA: Prentice Hall. 
Nunnally J. C. (1988). Psychometric Theory. New York: Macmillan College Publishing Co.

Pakistan Govt Ministry of Education. (2000). Literacy rate in Pakistan AEPAM. Retrieved from http://www.aepam.govt.pk.index.htm

Pakistan T. (2004). Literacy rate in Pakistan. Retrieved from http://www.Pakistan Times.com

Pollock, J., \& Waller, E. (1994). Day to day Dyslexia in the Classroom. New York: Routledge.

Prior, M. (1996). Understanding Specific Learning Difficulties. UK: Psychology Press Publisher.

Raven, J. C. (1956). Ravens Progressive Matrices. London: HK Lewis \&CO.

Shelly, D., \& Cohen, D. (1986). Testing Educational Tests. London: Croam Helin.

Stapleton, C. D. (1997). Basic Concepts in Exploratory Factor Analysis as a Test to Evaluation Score Validity: A Right Brainet Approach. Austin: South West Educational Research Association.

Swanson, H. C., \& Watson, B. L. (1989). Educational and Psychological Assessment of Exceptional Children. London: Merrill Publishing Co.

Vashist, S. R. (1993). Theory of Educational Measurement. New Delhi: Anmol Publishers.

Venn, J. J. (2000). Assessing Students with Special Needs (2nd ed.). New Jersey: Merrill, an imprint of Prentice Hall.

Walker, S. L. (2005). Development and Validation of the test of Geography related aptitudes. (Paper presented at Annual meeting of American Association of Geographers.

Washington, D. C. (1994). American Psychiatric Association. Diagnostic and Statistical Manual of Mental Disorders. Retrieved from http://www.priory.com/psych/ig.html

World Fact Book. (2002). Literacy in the Nations and Territories of the World. Retrieved from http://www.cia.govt/cia/publication/factbook 